\title{
Argonne treads carefully
}

\section{Washington}

IN an arrangement carefully crafted to avoid charges of federal meddling in industry, an investment fund set up by the University of Chicago has been used to start a company to market the laboratory's superconductivity technology. Officials say the arrangement marks the first time a US government laboratory has become involved in the creation and management of a private company.

Known as the Illinois Superconductor Corporation (ISC), the start-up company obtains one third of its initial $\$ 1.5$ million funding from the ARCH Development Fund, a venture-capital fund started by the laboratory and the University of Chicago, which runs Argonne for the Department of Energy. Additional funds come from the state and a private venture capital firm. The company is the first Argonne spinoff created by ARCH.

Although laboratory officials are careful to emphasize that federal dollars are not going directly to the company, but are filtered through $\mathrm{ARCH}$, the agreement is reminiscent of a deal that lost the chief of another federal agency his job last month. Craig Fields, head of the Defence Advanced Research Projects Agency (DARPA), was removed from his post after deciding that the agency should invest $\$ 4$ million in Gazelle Microcircuits Inc., a small semiconductor company.

For the conservative Bush administration, which favours free markets and Argonne National Laboratory and the

resists government intervention in industry, Field's move smacked of an "industrial policy" by which the government would decide to support one technology or company over another.

In the case of Gazelle, the technology was fast gallium arsenide microelectronics, a difficult but promising technique that has had trouble attracting traditional investors. By becoming a partner in Gazelle, DARPA - and the federal government - effectively became a very large and potentially unfair competitor in the industry.

What makes the Argonne start-up different, says ARCH director Steven Lazarus, is that the laboratory is driven solely by a wish to get its technology into the field, rather than the urge to support an ailing part of the industry. Six Argonne superconductor inventions will go into ISC's first product, a sensor to measure the temperature of refrigerants. Because the independently run ARCH - and not the laboratory directly - is the actual partner in the new company, other companies are unlikely to complain that they are forced to compete against the US government, Lazarus says.

Argonne puts $\$ 200,000$ a year into ARCH to find outlets for the laboratory's technology. If ISC becomes successful, a share of its profits will return to $\mathrm{ARCH}$, which will then return funds to Argonne's technology transfer programme to encourage further spinoffs.

G. Christopher Anderson BIOTECHNOLOGY INDUSTRY
Soviet doors opening up

\section{Leningrad}

IT has been cogently argued that of the many frustrations to research scientists in the Soviet Union, the worst is the sluggish flow of information from elsewhere: in a fast-moving field, not to know what others have already done, or tried and failed to do, is crippling. While the post, telephone and fax on the whole serve Soviet scientists rather ill, perhaps the most important device for the transmission of information is the international conference. So it is a significant achievement of the Institute of Cytology of the Academy of Sciences of the USSR to have brought to Leningrad last week some two dozen biologists from the United States, Europe and Japan (but mostly from the United States) to speak, along with about a dozen Soviet participants, on the highly topical theme of chromosome transmission and mitosis.

The idea for the conference seems to have arisen during a year-long visit by one of the organizers, Natalay Kouprina (Institute of Cytology, Leningrad) to the laboratory of co-organizer Phil Hieter at Johns Hopkins University in the United States; other members of the organizing committee were Vladimir Larionov and N. Nikolski at the Institute of Cytology, and William Earnshaw at Johns Hopkins.

Scientifically, the conference marked the early stages of a new assault on the macromolecular miracle whereby each time a eukaryotic cell divides, its microtubules assemble into a mitotic spindle that captures the paired and duplicated chromosomes and delivers one set reliably to each daughter cell.

Two traditional lines of attack on the problem may be expected to converge: many participants reported the identification of mutant yeast genes that affect the mitotic machinery so as to increase chromosome loss; many others contributed animal proteins that bind to the chromosomes themselves, or to the spindle microtubules, or both, and are thereby implicated as components of the machinery. The expectation is that some of the animal proteins will turn out to be the products of the genes defined in yeast.

The conference provided a forum for discussion of a central topic in cell biology at an exciting phase of its development when much of what is happening is not yet in print (but see Nature 345, 22 \& 345, 206; 3 \& 17 May 1990). This is the sort of thing Soviet scientists need. But it cannot have been conducive to Soviet participation in informal discussion that, in the retreat to the hard-currency hotel bar each evening, local participants were put in the invidious position of having to accept the hospitality of their guests.

Miranda Robertson 